\title{
Work and Consumption in Digital Capitalism: From Commod- ity Abstraction to 'Eidetisation'
}

\author{
Xavi Cava
}

Faculty of Philosophy, Universitat de Barcelona, Spain, xavicava@gmail.com

\begin{abstract}
The digital sphere can be studied as one of the most mature materialisations of the process of abstraction that accompanies capitalism. It is also a framework where subjectivity internalises the abstract form of commodities even further. In this sense, the Internet is the home of an abstract nature that is linked to a particular reification process that characterises post-Fordist production and consumption. This process can be named "eidetisation". My basic assumption is that the process of reification is being intensified with the digitalisation of the capitalist system. I will begin discussing the concept of reification as a specific form of alienation, stressing that the reification of society changes and intensifies in as much as capitalist production and consumption evolve. Then I will consider the process of abstraction as one of the main elements of reification. Finally, I will try to identify some distinctive traits within the process of "eidetisation".
\end{abstract}

Keywords: commodity, real abstraction, subjectivity, digital sphere, reification, eidetisation

Acknowledgement: I want to express my gratitude to Prof. Christian Fuchs and Denise Hansen at Westminster Institute for Advanced Studies (WIAS) for their help during my stay at the Institute. This article would not exist without their kindness.

"Socrates: Without anyone having taught him, and only through questions put to him, he will understand, recovering the knowledge out of himself? Meno: Yes.

Socrates: And is not this recovery of knowledge, in himself and by himself, recollection?

Meno: Certainly.

Socrates: And must he not have either once acquired or always had the knowledge he now has?

Meno: Yes.

Socrates: Now if he always had it, he was always in a state of knowing: and if he acquired it all some time, he could not have acquired it in this life. Or has someone taught him geometry? You see, he can do the same as this with all geometry and every branch of knowledge". Plato (1967)

"Throughout the ages of commodity production, from its initial form of ancient slave society to its ultimate capitalist completion, the products of manual labour are private property whereas the products of intellectual labour are social property. If an individual mind conforms to the elements of the real abstraction, by which society itself forms a functioning network and an economically viable system, then this mind is by itself capable of producing socially valid results. For this mind acts intellectually for society". Sohn-Rethel (1978) 


\section{The Abstract Dimension of Commodity: from Production to Final Consumption}

Reification has one of its ultimate sources in the commodity structure of both manual and intellectual labour (Lukács 1974). Lukács considers that wage labour is the origin of economic reification, and also that it accomplishes a determinant function in its spread from the sphere of production to other spheres of society. Accordingly, the strength of this movement seems to be directly proportional to commodification: that is, the expansion of the commodity to social areas not previously organised under the rules of exchange and private property. To put it in a simpler manner: the process of commodification must be accompanied by a simultaneous process of reification. They are not identical, but they appear together due to the abstract nature of commodity.

This abstract nature is always the same: it is not affected by the material characteristics of the objects to which it gives its form. The materiality of a commodity is not changed by value, but by the kind of work that adds value. From the point of view of capital, it is of minor importance whether if a commodity is a piano or a piano performance. But from the point of view of work as an activity and as a commodity, the nature of the commodity does matter. Reification of, and by, manual labour is not identical to reification of, and by, intellectual labour. Due to its cognitive nature, intellectual labour can reify and can be reified by a higher level of abstraction. Lukács illustrates this with the example of journalism. When a journalist sells his/her labour power, "it is precisely subjectivity itself, knowledge, temperament and powers of expression that are reduced to an abstract mechanism functioning autonomously and divorced both from the personality of their 'owner' and from the material and concrete nature of the subject matter in hand" (Lukács 1974, 100).

Moreover, in the sphere of production, the material bearer of value for capital is use-value and, in this sense, is just a means for its self-valorisation. But, in final consumption, use-value is relevant both for capital and labour. Its intimate coexistence with exchange-value leads the way for reification to appear in final consumption in very specific ways.

It is necessary to point out that work implies always some kind of (productive) consumption, and that there is always some expenditure of work on final consumption (like housework consumption that produces labour power). The productive dimension of consumption must be emphasised here. In his Grundrisse der Kritik der Politischen Ökonomie Karl Marx (1973/1858) sketched some elements of the dialectical relationship between productive activity and consumptive activity. The formulations of this dialectic in the Grundrisse bring to light the need to consider how the productive aspect of commodities consumption takes part in reification, particularly regarding the commodities that are produced and consumed by intellectual labour. In this reification lies a double level of abstraction that is characteristic of the present stage of capitalism: one owing to the abstract dimension of intellectual labour, and another to the abstract dimension of the commodity.

It is well known that the abstract nature of the commodity form is based on the fact that its appearance is twofold: as use-value and as value. Both are a result of the same labour. But this labour can be understood in two ways. As concrete labour, it produces the commodity in its material form. As abstract labour, it creates its value (Marx 1976/1885, 129). Such abstraction is not first mentally conceived and then applied to measure the work and to regulate the exchange activity: it emerges from the social relations in which capitalism is organised (Sohn-Rethel 1978). This abstraction cannot be experienced directly, but in its effects, and it has a determinant impact on the preconscious level of mind. 
The cognitive effects of commodity fetishism can be considered a consequence of the pre-conscious cognitive dimension of value. When commodities are exchanged in the market, their subjective prices oscillate around their objective value. Price is subjective, and it is consciously assigned, whilst value is objective, and it is pre-consciously formed. During exchange, the owners of commodities believe they are equating their prices, but actually they tend to equate their values: i.e., the average social quantity of abstract work deposited in each commodity. This abstract operation occurs each time they enter into an exchange relationship, but is far away from their awareness. The value appears to owners' consciences as a property of the commodities, as their objective character. And the value-based rules of exchanging appear as objective, natural laws. A relationship between people appears as a relationship between things (Marx 1976/1885, 165).

This phenomenon could not be possible without the potential of labour, and of the product of labour, to be considered something external from the worker: to be alienated. 'To alienate' has in this context a broad, economic sense, and a narrow, cognitive sense. In the economic sense, the alienation of labour means that the worker and his/her productive activity are separated. This productive activity needs to be objectified in order to be alienable and thus be treated as a commodity. Once it is appropriated as a commodity, such labour creates products that can logically also be appropriated and treated as commodities. This cognitive alienation, in labour, means that the separation between the owner and his/her commodity, and particularly between the worker and his/her labour power, takes the unavoidable appearance of something natural, even something necessary. This is one of the bases of what Lukács (1974) called the "reified consciousness". Material and cognitive alienation of work are two faces of a single process. The first deals with the social and economic dimensions of that process, and the second deals with cognitive and epistemological ones. They cannot be separated except in an analytical way. However, their theoretical distinction helps to show that abstraction is a process that works at different stages.

Abstraction dominates the exchange process in which labour power is sold by the worker and bought by the capitalist. The labour force hence becomes something that is separated, alienated from the worker: it becomes a commodity. But, at the same time, it does not cease to be an inherent part of the worker, because they cannot be physically separated. Therefore this separation (both as a commodity, and, inside it, as value and use-value) is of an abstract nature. It is experienced by the worker as the objectification, appraisement and quantification of a part of him/herself. This is not a physical, but an abstract detachment.

Nevertheless being abstract, the separation takes place in material acts and has material consequences. Once the labour force enters into the productive process, it ceases to be a commodity as its use-value is realised. It is objectified in concrete, productive labour, that creates concrete products. The labour force gives commodities their material form. But, in doing so, and at the same time, as abstract labour it injects value into the commodities produced. As active wage labour, the labour force gives objects their social, abstract form. In this case, the abstraction takes place outside the awareness of the worker. This abstraction is only noticeable from the point of view of capital, and it disappears once the work ends, only to reappear in the form of the final commodity, ready to be thrown into the market. That commodity is, once again, composed of a value and a use-value: an abstract continent surrounding a material content.

It would be a wrong conclusion to think that this last is the same former abstraction that appeared at the beginning of the process; that the abstraction has kept moving from phase to phase changing its aspect, but retaining its essence. Abstraction is a 
process, not a thing. As a process, it is created by human actions, and it ceases to exist when such actions are finished. It appears when the worker sells his labour power, and once the exchange has been completed, it ends. Abstraction appears a second time when labour power gives form to a new commodity, but once the activity is finished, it vanishes again. Abstraction is born again when that commodity is sold, and dies yet again when the exchange is realised. And there is abstraction for a fourth time when that commodity is consumed as a means to reproduce the labour force. Consumption, in capitalism, is mainly the consumption of commodities, and to a large extent, the production of the labour force as a commodity. It is a reproductive activity, but also a productive one. Final consumption is a special kind of work (unpaid and, in most cases, female work). The history of abstraction doesn't end with the valorisation of capital in the final purchase of the commodity. It follows on with the reproduction of the worker and the production of his/her labour power within consumption.

The reproduction of the worker and the production of labour power take place within the same process, but at different levels. The reproduction of the worker not only requires the purchase of commodities; it also needs his/her additional aggregated work. At the same time it is an abstract activity by which value is added by the worker to him/herself in the form of labour power. This means that he/she alienates a part of him/herself that must be produced and sold as a commodity. Such alienation is materialised in multiple ways: as time devoted to improve working skills, as the fostering of certain emotional dispositions and the repression of others, as strategic forms of socialisation inside companies, and so on. With this, the circle is closed. The labour power is produced as a commodity, and inasmuch as it requires at least some degree of self-alienation, such production is as abstract as that of any other commodity.

\section{The Transition of Reification towards Post-Fordism}

The intensity of commodity fetishism increases as the process of commodification colonises more spaces of everyday life. This is a quantitative increase that results in qualitative changes in the history of capitalism. It is what Lukács was facing in 1923 when he wrote his History and Class Consciousness. He believed that his contemporaneity was tending towards a whole reified society (Lukács 1974). His diagnosis was insightful in at least one point relevant to my hypothesis. The expansive dynamics of industrial capitalism tends to submit every social sphere under the corrosive consequences of commodification. In doing so, it impresses the abstract matrix of the commodity over more and more aspects of social existence. However, that abstraction is entangled not only with the commodity matrix, but also with the state of development of the productive forces. In 1923 that state rested on heavy industries, Taylorism and positivist science. Lukács concluded that, at that point of history, commodity abstractness appeared also as mechanical division of work, homogenisation, quantification and strict calculability. Today there is something more.

The successive steps by which abstraction embodies the commodity 'labour power' has been summarised below. The question now is to consider commodity abstraction, in its general appearance and its cognitive consequences, as a social phenomenon. This question points to what Lukács considered the core of commodity fetishism: the process of reification. He described it as a process by which the worker's labour and its results become autonomous entities, and appear as 'things' that tend to dominate even him/her (Ibid., 87). As commodities, they acquire a life of their own. This process of reification reaches what Lukács thought was its ultimate stage with Fordism. 
This idea is not far beyond Marx's analysis, some decades before Lukács. The specificity of Lukács is that he describes the way this process extends from the productive sphere to the rest of the social spheres. He relies on the work of Max Weber concerning the rationalisation and bureaucratisation of the modern state to postulate how both are linked to economic reification. It was not by chance that the abstract, quantitative, logical pattern of thought that emerges from commodity exchange, reappears in the organisation of the bureaucratic state. Lukács argues that there was a necessary link between them. And thus, the consciousness of the bureaucrats is reified in the same way as the consciousness of the workers:

"[...] the specific type of bureaucratic 'conscientiousness' and impartiality, the individual bureaucrat's inevitable total subjection to a system of relationships between the things to which he is exposed, the idea that it is precisely his 'honour' and his 'sense of responsibility' that exact this total submission, all this points to the fact that the division of labour which in the case of Taylorism invaded the psyche, here invades the realm of ethics. Far from weakening the reified structure of consciousness, this actually strengthens it". (Lukács 1974, 99)

That 'subjection' to a system of relationships between things which is characterised by rigidity, universality and abstractness, is also replicated - according to Lukács - in jurisprudence (law), in bourgeois Weltanschauung (philosophy), in positive science (epistemology) or in its applications by a mechanical, abstract technique ('bourgeois praxis'). In his view, this tendency gave to modern capitalist society its distinction as a society ruled by reification (Lukács 1974, 96 et seq.).

Almost a century after Lukács' diagnosis, the reification activity of commodity abstraction continues. It can even be said to have increased, as more spaces of social life have been colonised by commodification and digitalisation. The effects of reification are so generalised, that they appear as natural features. They bear a naturalised world of commodities from which the signs of its manufacture are occluded. Commodity abstraction is embodied in the largest part of social materiality (and virtuality).

Commodity abstraction has evolved at the same time as wage labour and productive forces. So has reification. Society under such 'intensified' reification has gone beyond the 'fully administrated society' glimpsed by Theodor Adorno, Max Horkheimer or Herbert Marcuse. The mechanical, quantifiable, predictable traits of reification that structured the Fordist system are still here, but mostly hidden in the deep mechanics of the productive system. Such traits still shape the capitalist structure of production at its most basic and technical level. However those traits neither appear in an obvious form in the most developed branches of production, nor reflect themselves as clearly as before in the appearance of the commodities produced there. They exist as a sociotechnical and cognitive substratum for workers and consumers. They are in the inner depths of a new kind of social productive metabolism (Beller 2003; Pasquinelli 2009; Terranova 2000).

At the same time the 'spectacular' experience of the commodified world has changed from its passive nature described by Lukács to a more interactive one (Briziarelli and Armano 2017). This has not occurred through a change of the abstract, spectacular form of the commodity, but through the commodification of subjectivity. As authors such as Negri (1991), Virno (2004) and Lazzarato (1997) have noted, in the postFordist stage of capitalism subjectivity is put to work. That means that, to a great extent, 
subjectivity is commodified directly or indirectly as labour power. Subjectivity is subsumed by post-Fordist capitalism as a productive as well as a consumerist subjectivity. And as long as both subjectivity and its environment, the world of commodities, mediate and are mediated by the same commodification process, they face each other as in a mirror that reflects the same reified gaze.

The modern subsumption of the subjective labour force bears its reverse in the intensification of the productive dimension of the final consumer. The figure of the 'prosumer' (Ritzer and Jurgenson 2010) and phenomena like Facebook are among the most evident examples of subjectivity's further reification at the side of consumption (Fuchs 2016). This 'aggregated' reification goes far beyond the influence of advertising and cultural industries. It has at least two sides. On one hand, as subjectivity is being colonised by the productive system, it must also be produced as labour force. Attributes like spontaneity, empathy, entrepreneurship or cooperation must be available to be sold as a part of the commodified labour force. And thus, such subjectivity must be at hand to be somehow evaluated, quantified and available for profitability. On the other hand, in its dimension of 'consumer that produces', the consumerist subjectivity aims to adapt its consumption activity to a maximising form for the productive system. It is not exact to say that any kind of final consumption is productive. To be productive in a capitalistic sense, consumption must lead, or contribute, to the production of a new commodity. An obvious example is the production of labour power. It must be stressed that there is nothing exactly new in this. It is just an implicit tendency in capitalist production that has found in its current stage (particularly with digitalisation and the extension of intellectual labour) the conditions to thrive.

\section{From the Hands to the Mind: Alfred Sohn-Rethel and the Real Abstraction}

Production and consumption are mediated by an abstraction. But this assertion doesn't coincide with everyday perception. Production, like exchange and consumption, is about real, actual activity. Assembling, typing, exchanging or drinking are all material acts. How can it be said that such acts have an abstract dimension? The reasonable answer seems to be that abstraction is born in the mind of assemblers, editors, exchangers and drinkers when they think about their actions. To put it in a paradigmatic example: they should think about their labour power as an abstract thing, as a commodity, before they sell it in the labour market. But, according to Sohn-Rethel (1978), in fact the opposite is true: there is an exchange abstraction, and it is something real. It is first created by the actions of sellers and buyers of commodities, and only later does it derive from their exchange activity to their minds. That leads him to assert that a real abstraction determines, historically, the mental process of abstraction.

Sohn-Rethel analyses the formal structure of the commodity and the act of exchange. He considers them as the result of a long historical process. Neither commodities nor exchange first appear in history in their finished, fully developed capitalist form. They evolve - as do their social effects. But commodity exchange, even in its more rudimentary stages, has a constant pattern at its core. By its nature, this kind of exchange creates a separation between the actual behaviour of its participants and the social function of exchange. The minds of the participants are individual and are focused on each concrete act of exchange and the material traits of each particular commodity. But their actions are social - although they are not aware of this social function. Sohn-Rethel locates the materialisation of real abstraction in this framework (1978, 26). In order to occur, in each actual act of exchange the commodity exchange needs use-value to be suspended, displaced by value. Use-value and value are not just contradictory, but are mutually exclusive in time, states Sohn-Rethel. The commodity is a 
material object which cannot be separated from its material features. That means that such features must be abstracted during the act of exchanging: they can't be present in the act itself. But the act of exchange is just about value, not about use-value. Participants want to exchange the commodities because of their use-values, but in the exchange they must only deal with their value. So, exchange is an abstract act at its social level. As the minds of its participants remain focused on the concrete elements of the commodity, in its use-value, the effect of such real abstraction affects their minds only after the exchange has been made (Ibid., 33). The real abstraction is thus reproduced everywhere and in every moment in which a commodity exchange is made throughout capitalist society.

Sohn-Rethel dissects the act of exchange and tries to show how this split is reproduced along each of its elements: the duration of the exchange (time), the required assumption that the commodity must remain unchanged throughout the process (space), the one-sidedness of each of the traders (that leads to what he calls "practical solipsism"), and so on (Ibid., 35 et seq.). For each of them, a practical abstraction from their material particularities (from the hic et nunc of each act of exchanging) takes place during the exchange. This abstraction is real because it is born in the acts of the participants, not in their minds, as Sohn-Rethel repeats once and again. And its ultimate historical core is the agreement that enables two commodities to be equated when exchanged. That is an important point: equality is not a trait that commodities possess, but something that is tacitly postulated by the process of exchanging. The commodities were not exchanged because they were equal; they were equal because they were exchanged. The agreement that makes possible the exchange is at some initial phase a more or less conscious relationship between human beings, but it develops in time and becomes cognitively transferred to the commodities, finally appearing as a relationship between the things. That is the core of the reification process (Ibid., 47). According to Sohn-Rethel, along its historical expansion, commodity exchange was the driving force in the development of quantification and abstract reasoning. It also had a decisive influence in the division between manual labour and intellectual labour (Ibid., 65-66).

The arguments of Sohn-Rethel are in some points very close to those of Lukács. But Sohn-Rethel separates abstraction in production from abstraction in exchange. He admits that there is some kind of abstraction in labour, but that it doesn't expand beyond production. It is the exchange abstraction which has the dominant social function. Hence, the exchange abstraction is the ultimate source that shapes the basic structures of prevalent modes of cognition in capitalist society, giving them their reified character. Sohn-Rethel argues that his methodological shift from production to distribution doesn't deny the main relevance of production in the economic perspective. It is a shift concerning only the epistemological perspective he is trying to ground. He is convinced that commodity exchange has a leading social function in the epistemological field due to its cognitive reifying effects. This is a hazardous argument that leads to some theoretical problems. Jappe (2013) points out that this step obliges Sohn-Rethel to deny the social epistemic function of labour. It even makes him deny the existence of abstract labour, thus undermining his Marxist conceptual base. Fuchs $(2016,179)$ also states that, although it helps to show the roots of the mechanical, quantifying capitalist reasoning, the overall position of Sohn-Rethel causes his epistemology to fall into an economic reductionism. Meanwhile, Toscano qualifies this reductionism, stressing that Sohn-Rethel differentiates between the economic fetishism of manual labour and the epistemological fetishism of intellectual labour: the first one is focused in value, the second one in logic $(2008,281)$. 


\section{The Real Abstraction in Consumption and its Naturalisation}

Notwithstanding these nuances, Sohn-Rethel provides some keys to extend the analysis of abstraction into the realm of modern consumption. As commodities become present in most of the social spheres, real abstraction strengthens its influence on each individual mind. It tends to homogenise the logic patterns of production and also of consumption. This tendency seems to increase as long as commodity and digital technology merge into a one-dimensional reality (Franklin 2012, 454). The resulting reification goes beyond the acts of exchanging: it is reproduced in the everyday interaction with each commodity and in the interaction with commodities as a whole (Postone 1993, 194). The reified commodified world, digital or not, appears as a natural environment. So the 'naturalisation' or 'normalisation' of a world made basically of commodities (a large part of them digital), is a result, and at the same time a requirement, for the expanded process of reification in modern capitalism (Franklin 2012, 457).

Through such naturalisation, the consumer recovers some familiarity with, some nearness to, and some sense of ownership of the commodity, though in a distorted and incomplete way. In consumption, reification cannot appear as a pure otherness, in the form of a world of completely alienated, estranged activity and estranged objects. Consumers need to make cognitive and emotional bonds with that world, because it is the world in which they live. In the consumer's world commodities reappear, but now with the appearance of something natural, thus shaping an environment in which each consumer finds him/herself, and with which he/she must interact embracing its apparently 'natural' laws. This effect is reinforced by the tendency of digital companies to provide technologies and devices that are more familiar and easier to use (Terranova [2000, footnote 47] provides a good example of this).

So the effects of real abstraction also expand inside consumption. This expansion can be detected in at least four ways:

1. The relationship of the consumer with the commodity is not only with its use-value, but also with its value. That happens before the act of exchange, as long as any commodity has a prohibition of use whilst still unpurchased: the consumer can observe it, desire it or evaluate it, but not use it. But the social dimension of value doesn't just vanish once the commodity is exchanged. Its presence usually persists even after the commodity has been purchased. And consequently, the relation with abstraction also persists. This tendency acquired a high social relevance with the development of mass production and mass consumption. Some authors have dealt in different ways with the effects of this abstraction; it has been considered as a mechanism of social distinction (Veblen 1970), as the emergence of a self-referring socio-symbolic system (Baudrillard 1996) or as a form for a new expression for the process of social inclusion/exclusion (Bauman 2005), to name a few. Real abstraction is born in the act of exchanging, but its effects remain in the commodity as long as consumers deal with its value. This persistence of real abstraction in consumption has important consequences in everyday cognition.

2. The tendency of capitalism towards expansion entails that a greater number of different object kinds are increasingly shaped by the commodity form, from food to care services, from identity-kits to online remembering spaces for the deceased. This implies that human experiences and human relationships, in most of their forms, are increasingly mediated by the commodity abstraction, and inversely, that experiences and relationships tend to lose other kinds of mediations. For many reasons, some things stay outside the commodification process. As long as these things can't be consumed as commodities, some of them tend to be occluded in a 
society ruled by exchange-value - and, with that, the possibility for such un-commodified things to be experienced is lost. Even when this is not the case, there is an unconscious tendency to consider them under the logic that entails real abstraction. The parousia (advent) of the commodity simultaneously in the objective, subjective and inter-subjective spheres, along with the depletion of non-commodities, lead to a biased culture where most objects and human relationships will be mediated only by the exchange abstraction. As the whole sphere of consumption is progressively identified with the world of commodities, real abstraction infiltrates most of the social experiences and transforms their concrete nature. This tendency is clearly perceived in digital technologies (Franklin 2012, 460; Berry 2014, 122).

3. Real abstraction is materialised in money (Sohn-Rethel 1978, 59). As capitalist society is increasingly commodified, the majority of social relations are increasingly monetarised. Consumers must adapt their everyday behaviour to the omnipresence of money. The use of money in almost every daily consumption intensifies the reification process and, in contemporary digitalisation, leads to its ultimate stage. In a time of virtualised commodities, real abstraction is so embedded in everyday life that it can discard its material body (Beller 2003, 100). Here money keeps its function as the universal commodity, but it doesn't need to be physically present in the exchange. Real abstraction doesn't weaken with this. Quite the opposite; it is strengthened, as money reveals itself in its pure, abstract form; an abstract form that nonetheless has been 'naturalised' and is part of everyday activity. It appears just like an eidos: a pure form separated from any physical root, a once-perceptible abstraction which everyone still recreates in its actions, although in fact it has been voided of materiality.

4. Contrary to Sohn-Rethel's claims, the process of abstraction in the productive sphere has epistemological effects at a broader social level. First, workers are compelled to identify themselves as commodities, as labour power that is exchanged for a wage. Second, abstraction appears in the hands of the workers (and their families) in a materialised form: as wages. Wages serve as the 'formal' naturalisation of money in their cognitive landscape. It is thanks to the monetised wage that they can perceive and interact with the world of commodities as with their knowable environment (Rekret 2016, 231). The wage is also the bridge that connects production with final, individual consumption. From a cognitive point of view, it is the link that allows real abstraction to affect in an uninterrupted continuity the minds of the workers/consumers. Sohn-Rethel underestimated the fact that, when labour is sold as a commodity, it can only be exchanged for a wage materialised into money. As the Native American wisdom says, 'You cannot eat money'. Money functions as the universal commodity, but its universality is a result of its abstract nature. That abstraction allows it to regulate consumption, but it cannot be consumed itself.

\section{Reification in the Digital Sphere: The Process of Eidetisation}

Let's take a step beyond the present discussion. In production, the prototypical figure of the passive, isolated worker attached to the mechanised assembly line is thus displaced by the new image of a networked, pro-active, self-realised producer (Terranova 2000). This model corresponds to a labour force that has to adapt and redo under the pressure of the new organisation of capitalist production; a labour force that now is not just exploited and alienated, but driven to a zealous cooperation in the process. At the same time the new worker has internalised abstraction as a part of his/her alleged own nature. To a certain extent, it can be said that the worker experiences a large part of 
the productive forces that surrounds him/her as if they were part of his/her own productive capacity (Franklin 2012). This productive activity becomes the externalisation of internalised abstraction. In the form of a commodity, the subjective dimension of the labour power becomes the abstraction of an abstraction. And, as a commodity, this labour power must be 'productively' consumed by the productive system in a new way (a way that doesn't need to be formal or explicit). The activity and results of the final consumption contain a double-degree abstraction that can be found materialised in countless ways: as a brand exhibited in a garment, a self-made 'cosplay' dress, or a Facebook profile, for example. Abstraction integrates both form and content of commodities (Toscano 2008, 285).

At the same time, a new consumer subjectivity has grown in the last decades. Such subjectivity acts as a passive receiver no more, but as a wishful participant of the process of reification. The upgraded abstraction of commodities needs from this new consumer a productive work of cognitive re-appropriation as well as of formal reincarnation. This more active consumption hardly sublates the tendency to abstraction. More often it just raises it to a new pitch, because the consumer can't relate to each commodity as an isolated object, but to all commodities as a whole world inside of which most meanings and uses are pre-established and interlinked: they share the same logic. With a few exceptions, meanings and uses are usually not created anew by the consumptive activity. They circulate from commodity to commodity, and consumers tend to act mainly as conveyances. Therefore abstraction is not overcome in consumption: it is just replaced by more abstraction. So subjectivity is lead to a distinctive process of reification in post-Fordism. The labour force goes beyond traditional wage labour and takes new forms, like digital labour (Fuchs 2014). This labour force is often exploited without being remunerated: moreover, frequently its exploitation is neither explicit nor evident. Through the activity of consumption the subjectivity becomes an active and productive part of the process of spectacularisation. Wishes, needs, ideas, the whole identity of the consumer can be commodified by means of his/her material activity of consumption (Tsogas 2012, 391).

This process finds its most suitable ground in the digital world. Or rather, the digital sphere evolves as a technical response to the need of the capitalist production system to expand itself beyond the objective world (I give the word 'objective' a very narrow sense here). Within the digital sphere, subjectivity finds a 'brave new world' to be expanded and to expand into. Digitalisation in capitalism is the process of transforming information about 'material' reality, commodified or not, into digital data, mostly commodified. So the digital world tends to increase commodification as it grows. To the same extent, subjectivity tends to be commodified as long as it explores and broadens the digital boundaries. This is not by chance, insofar as digitalisation is the ultimate material expression of the process of abstraction linked with commodity. As consumer subjectivity is immersed in the digital environment, it is progressively abstracted (Schirrmacher 2015, 147). It finds itself split between this abstracted side and its own materiality. And so it plunges deeper into reification.

From this point of view, the Internet fulfils in the sphere of consumption a similar feature to that of money in the sphere of exchange: it is a materialisation of the real abstraction. As Internet users search, express, interact and create new contents, they expand the digital space in a quantitative and also in a qualitative way. They use the Internet on the basis of their already reified cognitive background. At the same time, the Internet is a material and an abstract environment, both in its structure and in its content (Franklin 2012, 458). The uses of the Internet, although material, involve a high degree of abstract relationship. That results in a double degree of abstraction. The 
already abstract, commodified environment that appears as the 'normalised' digital reality is the first degree of abstraction. Inside it, the bulk of the activity of subjectivity experiences a subsequent process of commodification, becoming a second degree of abstraction. Fuchs has exemplified the dialectical nature of this process, showing that the abstract, commodified form of Facebook is hidden by its social use. It is what he calls an "inverse commodity fetishism" $(2016,67 ; 213)$. This is not the simple aggregation of a consumptive reification to productive and exchange reifications. It is a ramification of a strengthened real abstraction that tends to subsume more and more spaces of individual and social life.

The articulation of the abstract dimension of the commodity with its active and productive reception by the consumer, notably in the digital sphere, determines a stage of consumption in which the prototypical disposition is no longer that of passive attention, but one of active participation. Both dispositions are nourished by the cognitive influence of real abstraction. But in the first case it emerges from a commodity shaped to be perceived and contemplated, so its abstractness is transformed into an image. In the second case, the structure of the commodity demands from the consumer a disposition to actively contribute to its shaping, to the showing up of its form and content (Beller 2003). He/she must put his/her life at stake in this game.

But this requires that the commodified structure of the world of consumption appears not just as a spectacle, but as the resourceful continent of that life, as a dynamic social reality that falsely sublates its abstraction. The 'old' commodity as just an image (imago), as a ready-made representation whose main use is to be contemplated, is

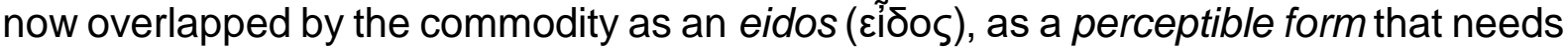
to be actively and productively consumed, both inside and outside the digital sphere. This perceptible form is a materialised abstraction that is created and exists in space and time. In such a form of eidos, the physical, utilitarian dimension of the commodity loses significance in face to its interactive, meaningful dimension. This duality can't be confused with the distinction between use-value and value, because they are present in both dimensions. Rather it must be understood as a predominance of the formal aspect of the commodity over its content, a predominance of the perceptual appearance of its abstract aspect over that of its concrete aspect.

Besides, an eidos isn't a fixed and finished form of the commodity. On the contrary, it mutates and changes over time. The consumption of this kind of commodity does not end up in its exhaustion, but mostly leads to its renewal, even to its revival in a different form (Terranova 2000, 47). Thus the activity of consumption loses the usual sharp distinction from production that characterises previous stages of capitalism, insofar as the consumer frequently is not the arrival point of the commodity, but rather some kind of transmuting interface or reproducing agent. The term 'prosumer' is very close to this idea, but it avoids the reference to the reification dimension, and usually it is narrowly focused on phenomena like Web 2.0 (Ritzer and Jurgenson 2010).

Although the eidos finds in the digital environment its most promising area, it can't be reduced to the Internet and social media. Inasmuch as the difference between production and consumption is blurred (Rekret 2016, 10; Terranova 2000, 35; Tsogas 2012 , 8), we can find it everywhere. For example, the logo of a brand on a jumper can give that jumper its eidetised form, as well as bless its wearer with the eideting function of proud consumer through the act of publicly wearing it. The reified image of a teen pop star may be grounds for a whole spectrum of commodities, from cosmetics to school supplies, which are also coated with the eidetised form of a designed personality to be embodied by thousands of teenaged consumers. 
In summary, it could be argued that eidetisation is a particular stage of reification, a process in which:

1. The abstract dimension of an existing commodity or set of commodities serves as the raw material to a further, increasingly abstracted commodification. In this process there must be, at least at some point, an activity of digitalisation.

2. It takes place mainly in the sphere of consumption, with the active participation of the consumer. The consumer acts, consciously or unconsciously, as a producer (in the sense of the activity of production/consumption).

3. It implies the strengthening of the reification of the subjectivity, as Lukács had stressed in the early twenties about the work of journalists (it affects the most intimate sphere of subjectivity, dimensions like 'knowledge, temperament and powers of expression').

These are some of the elements that I consider must be present in the process of eidetisation. There is no intention to formulate an ultimate definition about the process at this point: the concept is recent, and needs (and awaits) further discussion. Nevertheless, the final part of this article is devoted to clarifying the process of eidetisation a little more, observing it in a paradigmatic case: Facebook.

\section{The case of Facebook}

In Facebook the subjectivity of the user finds an (allegedly) open space to express and interact with other subjectivities. It does so in a digital environment almost totally naturalised, in which its technical, quantitative, abstract, commodified traits disappear behind the appearance of a free and immediate socialisation (Fuchs 2014, 258). The Facebook profile is used and lived by the consumer/producer as an extension of his/her identity. But, at the same time, it is also a digital commodity whose structure has been designed according to standards of quantification, calculability, computability and profit. The personal data that users upload are collected, filtered, and packaged as commodities, mostly in the form of audiences for the advertising industry. This means that part of the active consumption of the user is unpaid work that Facebook exploits. But that exploitation is just one side of the question. It could not exist if the user hadn't previously integrated the abstract nature of his/her digital environment as one main element of his/her subjectivity. The naturalisation of Facebook demands a subjective structure familiarised and fully integrated with the digital.

The activity of Facebook users is ruled by the spectacularisation of their working consumption and of their consuming work. As they update their profiles and chat with their friends, they are performing a productive activity that ends in a material, objective result: digital data. This activity is reflected in their own inner constitution (subjective sphere), as well as in the image of themselves they project and set up with other users (intersubjective sphere). They don't just produce technically computable data: they produce themselves in a subjective and digital form (Van Dijck 2013). This is part of the productive consumption activity described above. It is a consumption that not only uses up, but also produces: and in this case, the product is data, but so is the user. So, when users as consumers/producers of Facebook update their profiles, they are not just working as unpaid labour, nor just socialising with friends and contacts. They are also producing themselves as a digital workforce that is created and at the same time is consumed. Photos, comments, chats, 'likes', and so on are active consumption of Facebook, but at the same time are production of a reified identity in two ways: as a 
commodity that can be sold and purchased, and as a digital identity that adopts the form, the structure, the eidos of a commodity.

That second way can be a deliberate, conscious production; for example, when users take into account the impact that the information they upload can have in their professional life. But usually it is not so clearly conscious, because their activity is basically the self-production of their identities inside a predetermined, commodified technological device that appears as their normalised environment. To a large extent, most profiles are the result of eidetisation, of a process by which a previously commodified and spectacularised background (the formal structure of Facebook and the subjectivity of the user) is taken as the raw material for the production of a new commodity (the profile). That new commodity can adopt two main forms: a database created and commercialised as an audience and sold to advertising companies, and a part of the subjective labour power of the user.

Most of the users consider their profiles as a part of themselves, as an individualised feature that is part of their singular identity and that can't be equated to any other. But all the profiles correspond to the same technical and formal structure. Such structure is that of a commodity. It fits into the correspondence between one pattern and infinite copies that Walter Benjamin (2008) considered one of the main traits of the modern production system, especially in the communicative sphere. This productive pattern is at the roots of the digital world. Inside the digital sphere, the logic of serial production is taken to new limits. Hence, the structure of Facebook profiles is universal. All of them share the same formal pattern, and so does the digital identity of each user. That means that, in the end, all lead to a same model of experience mediated by the 'eidos'. Each personality in Facebook, no matter the spontaneity and creativity with which it is shown, has something of déjà-vu. Further, that spontaneity and creativity contribute to expand Facebook and diffuse its digital identities. So, they contribute to their homogenisation.

In conclusion, the experience of one's own digital identity is mediated by the eidetisation. The Facebook profile is a perfect example of the conversion of the self into a spectacle mediated by technological means. This is an active, self-generated conversion, channelised inside a technological and commodified system. This system is integrated by subjectivity as part of its naturalised environment. It turns the public, digital expression of life episodes, emotions, ideas and self-descriptions into something habitual. Such expressions must be transformed into digital data organised under a universal frame. The self is mediated by a homogeneous set of 'shares', 'likes', 'posts', 'links' and 'timelines': a digitalised show under the abstract pattern of a commodity. Thus, the user integrates digitalisation into his/her subjectivity as another dimension of his/her identity. He/she produces him/herself as an 'eidos'.

\section{References}

Beller, Jonathan. 2003. The cinematic mode of production: Towards a political economy of the postmodern. Culture, Theory and Critique 44 (1): 91-106.

Berry, David. 2014. Critical Theory and the Digital. London: Bloomsbury.

Baudrillard, Jean. 1996. The System of Objects. London: Verso.

Bauman, Zygmunt. 2005. Work, Consumerism and the New Poor. Maidenhead: Open University Press.

Benjamin, Walter. 2008. The Work of Art in the Age of Mechanical Reproduction. London: Penguin.

Briziarelli, Marco and Emiliana Armano, eds. 2017. The Spectacle 2.0: Reading Debord in the Context of Digital Capitalism. London: University of Westminster Press. 
Debord, Guy. 2012/1967. The Society of Spectacle. Eastbourne: Soul Bay Press.

Franklin, Seb. 2012. Cloud Control, or the Network as a Medium. Cultural Politics 8 (3): 443464.

Fuchs, Christian. 2016. Critical Theory of Communication: New Readings of Lukács, Adorno, Marcuse, Honneth and Habermas in the Digital Age. London: University of Westminster Press.

Fuchs, Christian. 2014. Digital Labour and Karl Marx. New York: Routledge.

Jappe, Anselm. 2013. Sohn-Rethel and the Origin of 'Real Abstraction': A Critique of Production or a Critique of Circulation? Historical Materialism 21 (1): 3-14.

Lazzarato, Maurizio. 1997. Lavoro immateriale. Forme di vita e produzione di soggettivitá. Verona: Ombre corte.

Lukács, Georg. 1974. History and Class Consciousness. London: Merlin Press.

Marx, Karl. 1976/1885. Capital: A Critique of Political Economy: Volume Two. London: Penguin.

Marx, Karl. 1973/1858. Grundrisse: Foundations of the Critique of Political Economy. London: Penguin.

Negri, Antonio. 1991. Marx Beyond Marx: Lessons on the Grundrisse. New York: Autonomedia.

Pasquinelli, Matteo. 2009. Google's PageRank Algorithm: A Diagram of the Cognitive Capitalism and the Rentier of the Common Intellect. In Deep Search: The Politics of Search Beyond Google, edited by Konrad Becker and Felix Stalder, 152-163. London: Transaction Publishers.

Plato. 1967. Plato in Twelve Volumes, Vol. 3. Translated by W.R.M. Lamb. London: Harvard University Press.

Postone, Moishe. 1993. Time, Labor and Social Domination: A Reinterpretation of Marx's Critical Theory. New York: Cambridge University Press.

Rekret, Paul. 2016. A critique of new materialism: ethics and ontology. Subjectivity 9 (3): 225-245.

Ritzer, George and Nathan Jurgenson. 2010. Production, consumption, presumption: The nature of capitalism in the age of the digital 'prosumer'. Journal of consumer culture 10 (1): 13-36.

Schirrmacher, Frank. 2015. Ego. The Game of Life. Cambridge: Polity Press.

Sohn-Rethel, Alfred. 1978. Intellectual and Manual Labour. A Critique of Epistemology. London: MacMillan Press.

Terranova, Tiziana. 2000. Free Labor: Producing Culture for the Digital Economy. Social Text 18 (2): 33-48.

Toscano, Alberto. 2008. The Open Secret of Real Abstraction. Rethinking Marxism: A Journal of Economics, Culture \& Society 20 (2): 273-287.

Tsogas, George. 2012. The commodity form in cognitive capitalism. Culture and Organization 18 (5): 377-395.

Van Dijck, José. 2013. 'You have one identity': Performing the Self on Facebook and Linkedln. Media, Culture and Society 35 (2): 199-215.

Veblen, Thorstein. 1970. The Theory of the Leisure Class: An Economic Study of Institutions. London: Allen and Ullwin.

Virno, Paolo. 2004. A Grammar of the Multitude. London: Semiotext(e)/Foreign Agents.

\section{About the Author}

Xavi Cava

Xavi Cava is a PhD candidate in the Faculty of Philosophy of the University of Barcelona and a member of the research group 'Crisi de la raó pràctica' at the same university. He is also a 
staff member of the journals Oxímora (http://revistes.ub.edu/index.php/oximora/index) and Astrolabio (http://www.raco.cat/index.php/Astrolabio). His research interests include the study of consumption. 